ANUARIO DE EstUdios MEDIEVALES

51/2, julio-diciembre de 2021, pp. 713-742

ISSN 0066-5061

https://doi.org/10.3989/aem.2021.51.2.08

\title{
EL MAUSOLEO DE LA DINASTÍA TRASTÁMARA \\ EN LA CATEDRAL DE TOLEDO
}

\author{
THE MAUSOLEUM OF THE TRASTÁMARA DYNASTY \\ IN THE CATHEDRAL OF TOLEDO
}

\author{
PABLO GUMiEL CAMPOS \\ Universidade Nova de Lisboa - \\ Parques de Sintra Monte da Lua S.A. \\ https://orcid.org/0000-0001-9632-8358
}

Resumen: El rey Enrique II de Castilla (1366-1379), fundó por orden testamentaria una capilla real en la catedral de Toledo que durante varias generaciones actuó como el panteón real de la familia Trastámara. Esta capilla real fue abandonada en el siglo XVI, y tan solo los sepulcros originales fueron preservados tras su traslado a la Capilla de Reyes Nuevos de la catedral primada. El objertivo de este artículo es realizar un estudio documental y arquitectónico que nos permita conocer cómo era la estructura y composición original de este mausoleo bajo medieval.

Palabras clave: Enrique II; capilla real; Toledo; dinastía Trastámara; arquitectura medieval.

Abstract: In his will, King Henry II of Castile (1366-1379) founded a royal chapel in the Cathedral of Toledo, which for generations acted as the royal pantheon of the Trastámara family. This royal chapel was abandoned in the $16^{\text {th }}$ century and the original tombs were only preserved after their transfer to the Capilla de Reyes Nuevos in the cathedral. The aim of this paper is to carry out a documentary and architectural study that will clarify our knowledge of the original structure and composition of this late medieval mausoleum. Keywords: Henry II of Castile; royal chapel; Toledo; Trastámara dynasty; medieval architecture.

\section{SUMARIO}

1. Historiografía.- 2. Historia documental del mausoleo Trastámara en Toledo.3. Estudio arquitectónico.-3.1. La sala de la torre.-3.2. El coro de la capilla.-3.3. El panteón regio.- 3.4. La cubrición de la capilla, origen gótico y posterior artesonado plano de piñas.- 4 . Conclusiones.- 5. Bibliografía citada.

\section{HISTORIOGRAFÍA}

La capilla real fundada por Enrique II en la Catedral de Toledo ha sido abordada de forma puntual por numerosos investigadores, pero aún no se ha llevado a cabo un análisis en profundidad acerca de cómo pudo ser en origen, o de cuál fue la evolución constructiva de la misma. 
El primer y principal problema al que hay que hacer frente cuando focalizamos una investigación sobre este ámbito, es la ausencia del mismo. Tan solo una pequeña cubierta de mocárabes que hoy se conserva en la Capilla del Tesoro de la Catedral ha sido relacionada con la estructura primitiva de la capilla, aunque incluso ésta plantea ciertas dudas como veremos. Ante esta ausencia casi total de restos arquitectónicos, la principal base documental en la que se sostienen todos los estudios sobre el mausoleo Trastámara es un plano muy sintético del siglo XVI atribuido erróneamente a Diego Vázquez (fig. 1) 1 $^{1}$ Lo primero que debemos hacer por lo tanto es esclarecer esta constante historiográfica.

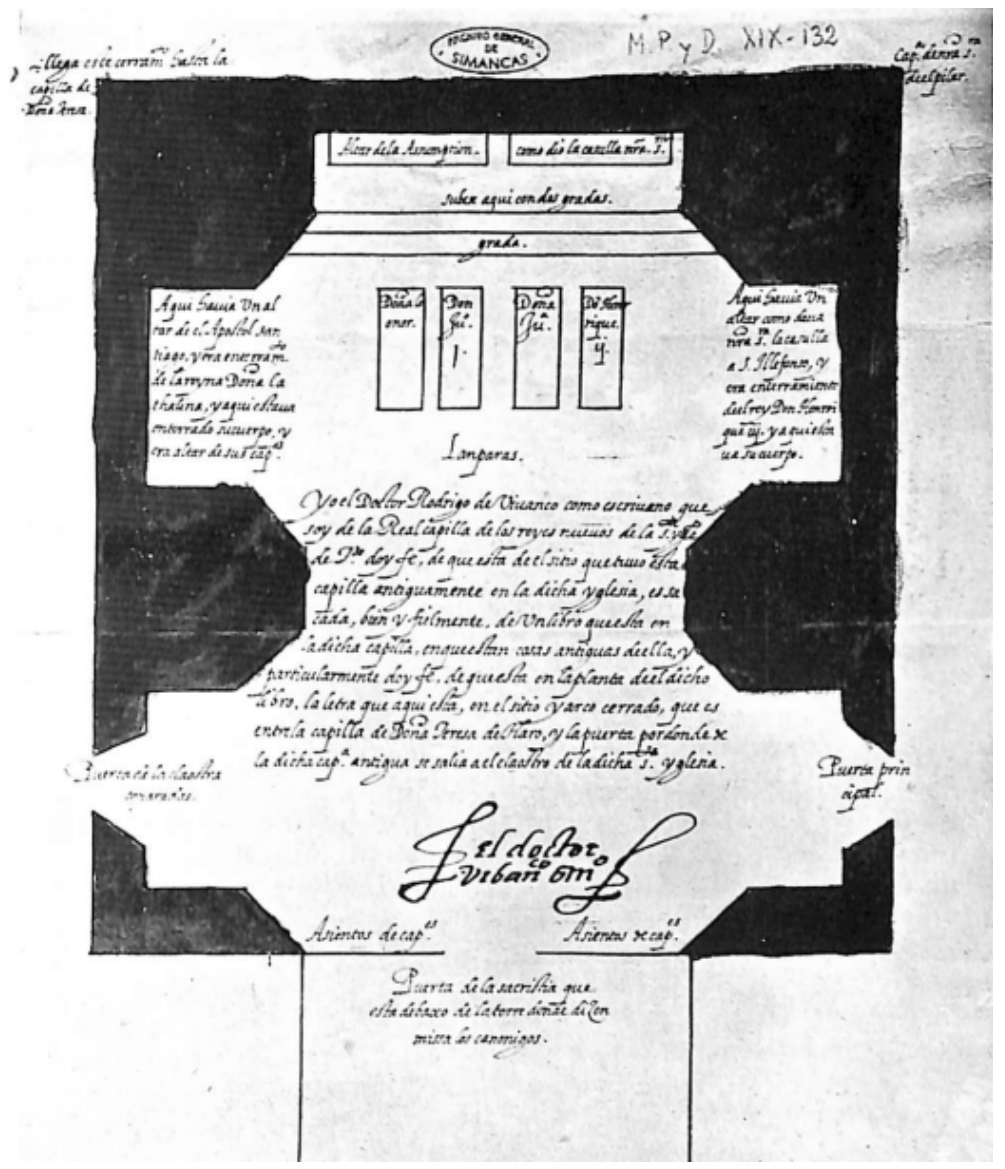

Fig. 1. Plano de la Capilla Trastámara de Toledo recogido por Juan López de León en el siglo XVI.

${ }^{1}$ Arellano 2010, p. 21. 
Como afirma Mario Arellano García, Diego Vázquez de Contreras fue capellán de la Capilla de Reyes Nuevos desde el 2 de julio de 1544, y por lo tanto no contempló el traslado de la misma acontecido en 1534. El capellán Diego Vázquez es el autor de un manuscrito datado en 1586, intitulado Constituciones del Emperador Carlos, y que se custodia en el archivo de la Capilla de Reyes Nuevos. En este manuscrito, el autor recoge un plano esquemático acompañado de un texto descriptivo sobre la capilla primitiva. Sin embargo, como observó Mario Arellano García, en el mismo manuscrito el propio Diego Vázquez reconoce que la descripción no es suya sino de Juan López de León².

Juan López de León fue capellán de Reyes con anterioridad a 1534, y por lo tanto él sí presenció o pudo presenciar el traslado de la capilla. Como observa Arellano García, parece que Diego Vázquez pasó a limpio el texto de Juan López de León intitulándolo como Copias de papeles curiosos de la Capilla de Reyes Nuevos de Juan López de León capellán contador en ella sacados 15 de septiembre $1565^{3}$. El manuscrito de Juan López de León, pasado a limpio por Diego Vázquez, constaba de dos páginas. La primera página contenía un texto que rezaba:

Descripción de la Capilla antigua y como estaban en ellas las sepulturas de los gloriosos reyes por que sé que muchas personas lo desean saber y yo lo prometí descrivillo y para que mejor se entienda encargue a un amigo pusiese en planta aquel lugar como aparece en la plana siguiente, en la que se han de considerar en el lugar del altar mayor, dos altares mayores iguales en todo, divididos y apartados por medio con muy poco hueco y unas cortinas voladas de la pared con que aunque estuviese diciendo misa en ambos altares no se viese un sacerdote al otro, el altar tenia por retablo como dio Ntra. Sra. su casulla a san Ilefonso y el otro la Asunción de la Virgen 4 .

En la segunda hoja encontramos la representación de este plano esquemático con una serie de anotaciones que analizaremos con detenimiento más adelante. Como menciona Juan López de León, el croquis fue realizado por un amigo suyo, sin embargo el autor del mismo sigue representando una incógnita y por lo tanto de aquí en adelante, para facilitar la comprensión, lo llamaremos el plano de Juan López de León.

La siguiente fuente historiográfica de relevancia también se remonta al siglo XVI. En el año 1549 el Doctor Blas Ortiz, escribió Descripción Graphica y Elegantisima de la S. Iglesia de Toledo ${ }^{5}$. Blas Ortiz fue un destacado

2 Ibidem.

3 Arellano 2010, p. 22.

4 Ibidem.

5 Blas 1999. 
personaje de la sociedad toledana de la primera mitad del siglo XVI especialmente reconocido en los círculos eclesiásticos. De hecho, como veremos más adelante, el doctor Blas Ortiz participó en el traslado de los cuerpos reales desde la capilla antigua hasta la nueva obra de Covarrubias. El autor durante su recorrido por el templo, se detiene unas líneas para hacer mención a la nueva Capilla de los Reyes Nuevos recopilando la epigrafía de los sepulcros.

Un siglo más tarde encontramos otra obra de suma importancia para la historiografía. Su autor fue Cristóbal Lozano, un sacerdote, dramaturgo y poeta del Siglo de Oro español que vivió entre 1609 y 1667. La obra, intitulada Los Reyes Nuevos de Toledo ${ }^{6}$, no fue publicada sin embargo hasta 1734. El clérigo llevó a cabo un estudio de las vidas de los Trastámara en el que se incluye un análisis de la localización, fundación y distribución espacial del mausoleo. Lozano hará una primera aproximación a la que pudo ser su distribución espacial, basándose fundamentalmente en el boceto de Juan López de León y cierta diplomática de los siglos XIV y XV.

La historiografía del siglo XIX y la primera mitad del siglo XX se basan en los principios establecidos por Cristóbal Lozano y no aporta grandes contribuciones al estudio del edificio. Se trata de obras de carácter genérico que abarcan el cómputo global de la catedral o incluso el panorama arquitectónico completo de la ciudad de Toledo. Son especialmente reseñables los trabajos de José Amador de los Ríos, con su importante libro Toledo Pintoresca o descripción de sus más celebres monumentos ${ }^{7}$. También destacable es una obra con esencia de catálogo redactada en 1919 por el Conde de Cedillo, Jerónimo López de Ayala-Álvarez, donde se realiza de nuevo una recopilación de la epigrafía de los sepulcros de la Capilla de los Reyes Nuevos ${ }^{8}$. Por último no debemos dejar de mencionar uno de los primeros monográficos dedicados a la Catedral de Toledo del historiador del arte y director de la colección Ars Hispaniae Josep Gudiol Ricart ${ }^{9}$.

A mediados del siglo XX, vemos aparecer sin embargo una serie de publicaciones de suma importancia que van a aportar nuevos datos a la historiografía sobre el mausoleo Trastámara. En el año 1945 Filemón Arribas extrae del archivo de Simancas, una serie de noticias y documentos referentes al periodo de demolición de la capilla primitiva a partir de las que va a esclarecer las fechas de desaparición de la misma ${ }^{10}$. Algo más tarde, en 1954,

${ }^{6}$ Lozano 1734.

${ }^{7}$ Amador de los Ríos 1845.

${ }^{8}$ López de Ayala-Álvarez de Toledo 1919.

9 Gudiol 1947.

${ }^{10}$ Arribas 1944-1945, pp. 205-207. 
Ricardo del Arco publicará Sepulcros de la Casa Real de Castilla ${ }^{11}$, una importante investigación sobre los mausoleos, sepulcros y capillas de los reyes castellanos. Finalmente en 1975, Hidalgo Lucero, publicará un primer artículo monográfico en el Boletín Oficial del Arzobispado de Toledo sobre la capilla primitiva de Enrique $\mathrm{II}^{12}$. Podemos aventurarnos a decir que hasta hoy en día la obra de Hidalgo Lucero es la investigación más completa que se ha realizado sobre el panteón real.

En la segunda mitad del siglo XX otra serie de autores mencionan de nuevo la capilla en manuales de arquitectura toledana, o monografías sobre la Catedral. Hago referencia a investigaciones como la de Fernando Chueca Goitia $^{13}$, Ángela Franco ${ }^{14}$, la tesis doctoral inédita de Ignacio de las Casas ${ }^{15}$, o los trabajos de Teresa Pérez Higuera ${ }^{16}$. La profesora Pérez Higuera también publicó un estudio fundamental en el año 1985 en la revista Teckné. En este artículo se plantea una reformulación de las fechas de datación de los sepulcros y se esclarece la autoría de los mismos, arrojando mucha luz sobre el conocimiento del desaparecido edificio ${ }^{17}$.

El siglo XXI se estrena con una obra básica sobre arte medieval hispano. El catálogo de la exposición Maravillas de la España Medieval. Tesoro sagrado y monarquía dirigida por el profesor Isidro Bango. En esta obra encontramos dos capítulos que abordan colateralmente el estudio de la capilla real de Enrique II en Toledo. En el primero de ellos ${ }^{18}$, Concepción Abad, insistió en que la estructura del mausoleo debía estar decorada con una estética de raigambre hispanomusulmana muy similar a la de Córdoba. El otro capítulo de interés para nuestro estudio, fue redactado por Margarita Pérez Grande ${ }^{19}$.

Finalmente, la última pieza historiográfica significativa en cuanto a su análisis arquitectónico es un artículo de Juan Carlos Ruiz Souza ${ }^{20}$ en el cual se realiza una comparativa entre las distintas capillas funerarias de carácter regio en el reino de Castilla y León, centrándose en concreto en Sevilla, Toledo y Córdoba. En lo referente a la capilla que estamos estudiando, Ruiz Souza, focaliza su mirada en la bóveda de mocárabes conservada hoy en día bajo la torre. El autor plantea que la estética hispanomusulmana en el espacio

\footnotetext{
${ }_{11}$ Del Arco 1954.

12 Hidalgo 1975.

3 Chueca 1981.

14 Franco 1991.

15 De las Casas 1992.

16 Del Cerro 1992.

17 Pérez Higuera 1985.

${ }_{18}$ Abad 2001, p. 67.

19 Pérez Grande 2001.

${ }^{20}$ Ruiz 2006.
} 
aparentemente más irrelevante del edificio nos debería dar pie a entender cuál pudo ser la estructura oriental del mausoleo.

Se puede afirmar que, en lo que refiere al ámbito arquitectónico, la publicación de Ruiz Souza representa la máxima aportación en este recorrido historiográfico desde el siglo XVI. Pero de igual manera, la publicación de Mario Arellano García que ya hemos mencionado al inicio de este capítulo, da la vuelta a todo el conocimiento documental del mausoleo fundado por Enrique II. Desde 2008 este último autor, en compañía de Jaime Colomina, llevó a cabo la catalogación del archivo de la Real Capilla de los Reyes Nuevos. Sus indagaciones, publicadas en Toletum, sacaron a la luz la mencionada falsa atribución del plano de Juan López de León a Diego Vázquez ${ }^{21}$.

Podemos mencionar unos últimos trabajos de notoriedad en el siglo XXI que siguen dos vías de estudio: por un lado los trabajos artístico-arquitectónicos que han seguido renovando la información ya obtenida, recopilándola en nuevos manuales sobre la Catedral de Toledo o aportando datos sobre épocas diferentes a la Edad Media. En este contexto debemos mencionar a autores como Jaime Colomina Torner ${ }^{22}$, Laura Canabal Rodríguez ${ }^{23}$, José González Romero $^{24} \mathrm{o}$ Ángela Franco Mata ${ }^{25}$. Por otro lado, se ha ido desarrollando otra vía de investigación distinta que ha abordado el estudio de la capilla como institución político-eclesiástica. Un análisis de los capellanes, y las funciones de los mismos al servicio de los reyes. Los principales historiadores al respecto han sido Óscar Villarroel González ${ }^{26}$, María José Lop Otín ${ }^{27}$ y David Nogales Rincón ${ }^{28}$.

\section{Historia DOCUMENTAL DEL MAUSOLEO TRASTÁMARA EN TOLEDO}

Una vez expuesta la historiografia del monumento, vamos a resumir la historia documental de la capilla (fig. 2). Consideramos fundamental llevar a cabo esta recopilación para con ello trazar la historia constructiva del mausoleo. Son numerosos los acontecimientos que tienen lugar entre su fundación en 1374 y su abandono a finales del siglo XVI. Las pruebas documentales de entierros, funerales, dotaciones o financiación, extraídas de las crónicas y la diplomática, nos facili-

\footnotetext{
${ }^{21}$ Arellano 2010.

22 Colomina 2003.

${ }^{23}$ Canabal 2007.

${ }^{24}$ González Romero 2014.

${ }^{25}$ Franco 2010.

26 Villarroel 2008.

${ }^{27}$ Lop 2008.

${ }^{28}$ Nogales 2009.
} 
tarán además la comprensión sobre cuál pudo ser el estado artístico-arquitectónico en el que se encontraba la capilla a lo largo de sus doscientos años de existencia.

\begin{tabular}{|c|c|}
\hline 29 mayo 1374 & $\begin{array}{l}\text { Fundación de la Capilla Real por parte de Enrique II y dotación } \\
\text { (aparentemente no efectuada) de } 12 \text { capellanes para la misma. }\end{array}$ \\
\hline 29 mayo 1379 & Muerte de Enrique II de Castilla. \\
\hline Febrero 1380 & $\begin{array}{l}\text { Entierro de Enrique II en la capilla fundada por él mismo en la } \\
\text { Catedral de Toledo. }\end{array}$ \\
\hline 27 marzo 1381 & $\begin{array}{l}\text { Fallecimiento y entierro de Juana Manuel, esposa de Enrique II } \\
\text { de Castilla, madre de Juan I. }\end{array}$ \\
\hline 1382 & $\begin{array}{l}\text { Dotación de Juan I a la Capilla Real con } 25 \text { capellanes, } 12 \text { de ellos } \\
\text { para su padre y } 13 \text { para su madre. }\end{array}$ \\
\hline 13 agosto 1382 & $\begin{array}{l}\text { Fallecimiento y entierro de Leonor de Aragón, esposa de Juan I } \\
\text { de Castilla, madre de Enrique III. }\end{array}$ \\
\hline 21 de julio de 1385 & $\begin{array}{l}\text { Testamento de Juan I de Castilla ordenando ser enterrado en la capilla } \\
\text { que fundó su padre en la Catedral de Toledo. }\end{array}$ \\
\hline 9 octubre 1390 & Fallecimiento y entierro de Juan I de Castilla. \\
\hline 1391 & $\begin{array}{l}\text { La capilla se queda sin financiación a consecuencia de los ataques a } \\
\text { la judería de Toledo, lugar de donde eran extraídos los fondos para su } \\
\text { mantenimiento. }\end{array}$ \\
\hline 24 diciembre 1406 & $\begin{array}{l}\text { Enrique III ordena en su testamento que sus descendientes terminen } \\
\text { la capilla en la que él se está ordenando enterrar y que las estatuas de } \\
\text { los sepulcros sean finalizadas. }\end{array}$ \\
\hline 25 diciembre 1406 & Enrique III fallece y es enterrado en la Capilla Real. \\
\hline 17 agosto 1415 & $\begin{array}{c}\text { Catalina de Lancaster funda una nueva capilla dentro de la Capilla de } \\
\text { Reyes Nuevos. Es posible que las obras fueran finalizadas. }\end{array}$ \\
\hline 2 junio 1418 & $\begin{array}{l}\text { Fallece Catalina de Lancaster, esposa de Enrique III } \\
\text { y madre, de Juan II y es enterrada en la Capilla Real. }\end{array}$ \\
\hline 1446 & $\begin{array}{c}\text { La capilla recupera su financiación al concederle Juan II las rentas de } \\
\text { los arciprestazgos de Illescas, Canales y Rodillas. }\end{array}$ \\
\hline 1531 & $\begin{array}{l}\text { El arzobispo Fonseca decide trasladar la Capilla y saca el proyecto de } \\
\text { la nueva construcción a concurso. El proyecto es adjudicado a Alonso } \\
\text { de Covarrubias. }\end{array}$ \\
\hline 1534 & La obra de Covarrubias es concluida e inaugurada. \\
\hline 28 mayo 1534 & $\begin{array}{c}\text { Los cuerpos de los reyes y reinas son trasladados a la capilla de los } \\
\text { Reyes Nuevos construida por Covarrubias. }\end{array}$ \\
\hline 28 mayo 1534 & $\begin{array}{c}\text { Aparentemente es iniciada la destrucción del mausoleo por parte } \\
\text { del Mariscal de Navarra, pero probablemente paralizada y tapido el } \\
\text { espacio interior. }\end{array}$ \\
\hline 2 julio 1544 & $\begin{array}{l}\text { Diego Vázquez es nombrado capellán mayor de la Capilla de Reyes } \\
\text { Nuevos. }\end{array}$ \\
\hline 1586 & $\begin{array}{l}\text { Diego Vázquez escribe Constituciones del Emperador Carlos donde } \\
\text { transcribe por primera vez el plano de la capilla realizado años antes } \\
\text { por Juan López de León. }\end{array}$ \\
\hline 1587 & $\begin{array}{l}\text { Los capellanes solicitan la restauración de la capilla primitiva de } \\
\text { Enrique II para trasladar allí a los capellanes de la reina Catalina } \\
\text { de Lancaster. La solicitud es desestimada. }\end{array}$ \\
\hline
\end{tabular}

Fig. 2. Resumen de las fuentes para el estudio del mausoleo Trastámara en Toledo. 
Como observó por primera vez Cristóbal Lozano ${ }^{29}$, el rey Enrique decidió fundar una capilla real para su enterramiento y el de sus descendientes en el lugar donde se apareció la virgen a San Ildefonso, esto es, según la tradición el segundo pilar de la nave más meridional del templo catedralicio. El primer documento en el que encontramos mención a la capilla es el propio testamento del rey Enrique, redactado en el año 1374 y cuya clausula segunda expone:

Lo segundo mandamos este nuestro cuerpo, que nos dio Dios, á la tierra de que fue fecho é formado, para que sea enterrado honradamente, como de Rey, en la Iglesia de Sancta Maria de Toledo, delante de aquel lugar do anduvo la Virgen Sancta Maria é puso los piés quando dió la vestidura á Sancto Alfonso: en la qual nos avemos muy grand fiucia é devoción, porque nos acorrió é libró de muchas priesas é peligros, quando lo ovimos menester. E mandamos é tenemos por bien que en el dicho lugar sea fecha una capilla la mas honrada que ser pudiere, é que sean y puestas é establecidas doce capellanías perpetuas, é canten, é digan los capellanes dellas cada dia misas é las otras horas canónicas por la nuestra ánima que la quiera Dios perdonar. E estos doce capellanes que ayan su salario cada año, cada un capellan mil é quinientos maravedis por el tercio del año. E que sean puestas guardas, é sacristan, é ornamentos en la dicha capilla, é todas las otras cosas que fueren necesarias, segund que están puestas é ordenadas en la capilla del Rey Don Alfonso, nuestro padre, que Dios perdone, que está enterrado en la cibdad de Cordoba. E para cumplir é pagar cada año los salarios de los dichos capellanes, é guardas, é sacristan, é las otras cosas que fueren menester para la dicha capilla, asinámosles que ayan é los sean pagados los maravedis que en ello montaren de cada año para siempre de la cabeza del pecho de los Judios de la dicha cibdad de Toledo, bien é complidamente por los tercios del año, segund dicho $\mathrm{es}^{30}$.

Cinco años más tarde, el día 29 de mayo de 1379, Enrique II fallecía. Según la crónica de López de Ayala, el rey don Enrique, en su lecho de muerte tuvo la siguiente conversación con Don Juan García Manrique, obispo de Sigüenza:

E entonce le dixo Don Juan Garcia Manrique, Obispo de Siguenza: "Señor, ¿en qué logar vs mandades enterrar?" E dixo: "En la mi capilla que fice en Toledo, en hábito de Sancto Domingo de

29 "Repare ahora el curioso en la elección de sitio tan soberano que hizo este piadoso, y devoto Príncipe (...) Porque si en aquel lugar, y espacio, en que se hizo la Capilla, dice la cláusula del Rey (fundado, claro está, en la antigua tradición), que anduvo la virgen Sancta María y puso sus pies, ¿puede aver tierra más sagrada en cuanto circunda la redondez de la tierra?”. Lozano 1734, p. 67.

${ }^{30}$ López de Ayala, Crónica del Rey don Pedro I, p. 39. También hemos contrastado el texto de Pedro López de Ayala con un traslado del testamento de Enrique II de 1408, Testamento de Enrique II (29/5/1374) -Archivo General de Simancas, Patronato Real, Capitulaciones con Aragón y Navarra, leg. 29, doc. 32-. 
la Orden de los Predicadores, ca fué natural deste mi Regno, é los Reyes de Castilla mis antecesores siempre ovieron Confesor desta Orden. E como quier que quando yo era Conde avia confesor de los Predicadores" $" 31$.

Una vez finado el rey, su cuerpo fue trasladado desde Santo Domingo de la Calzada hasta la Catedral de Burgos, donde, acompañado del nuevo monarca, su hijo Juan I (1379-1390), fue depositado en la capilla de Santa Catalina. De Burgos su cuerpo fue trasladado a Valladolid, y finalmente fue depositado, según tradicional afirmación, en la misma capilla que él había mandado erigir en la Catedral de Toledo. La fecha de su entierro definitivo es un punto controvertido. Según Ricardo del Arco la inhumación habría tenido lugar a finales de $1379^{32}$. Para Teresa Pérez Higuera el entierro no se realizó sin embargo hasta febrero de $1380^{33}$. De hecho, la autora argumenta como los sucesivos traslados que el féretro tuvo parecen indicar que la capilla no se había terminado a fecha de su muerte en mayo de 1379 y que hasta entrado 1380 el mausoleo no estaba en condiciones para poder enterrar los restos del rey.

En marzo de 1381 falleció la reina Juana Manuel, esposa de Enrique II y fue enterrada junto a su marido bajo órdenes de su hijo Juan I:

En este año estando el rey Don Juan en la cibdad de Salamanca, despues que ovo declarado tener que Clemente VII era verdadero Papa, finó la Reyna Doña Juana su madre, miércoles veinte é siete días de marzo deste año: é levaron su cuerpo á enterrar á la cibdad de Toledo en la capilla que y ficiera el Rey don Enrique su marido en la Iglesia de Sancta María la mayor ${ }^{34}$.

Tras el fallecimiento de su madre, Juan I realiza una dotación para la capilla en el año 1382. Los autores coinciden que la dotación que Enrique II realiza bajo su testamento no debió de hacerse efectiva, y que es en tiempos de Juan I cuando la capilla entra en pleno funcionamiento. En palabras de Cristóbal Lozano: en vida de este Rey se fabricó la Capilla, digo el edificio de ella; pero aver Capellanes con renta, no se sabe los hubiese hasta su hijo el Rey Don Juan el Primero ${ }^{35}$. En este año de 1382, Juan I elevó el número de capellanes que Enrique II había instituido en su testamento, de doce a veinticinco, doce de los cuales irían dirigidos a su padre y trece para su madre. Expongo las propias palabras del Juan I, recogidas por Hidalgo Lucero en 1975:

${ }^{31}$ López de Ayala, Crónica del Rey Enrique Tercero, p. 38.

32 Del Arco 1954, p. 314.

${ }_{33}$ Pérez Higuera 1985, p. 132.

${ }^{34}$ López de Ayala, Crónica del Rey don Juan Primero, p. 151.

${ }^{35}$ Lozano 1734, p. 67. 
Por ende ordenamos e tenemos por bien que aya de aquí adelante, en la nuestra capilla que el rey nuestro padre mando fazer, que Dios perdone, en la iglesia cathedral de Toledo, ciertas capellanías e otras cosas que entendemos que cumplen, para ser mexor revividas e honradas las dichas capellanías; lo qual todo ordenamos e mandamos que se cumpla en esta manera y con estas condiciones que se sigue: primeramente que sean veinte y cinco capellanes, los doce por el dicho rei nuestro padre, y los trece por la dicha reina doña Juana, nuestra madre, que Dios perdone ${ }^{36}$.

En agosto de 1382 falleció la reina doña Leonor, esposa de Juan I, y fue enterrada bajo órdenes del propio rey en la misma capilla:

E estando allí sopo nuevas como la Reyna Doña Leonor su muger era finada, é que moriera en la villa de Cuellar de parto de una fija que encaescio, la qual vivió poco tiempo despues. (...) E el rey mandó traer el cuerpo de la Reyna Doña Leonor su muger a la cibdad de Toledo, é fue y enterrado en la Iglesia de Sancta Maria en la capilla que fizo el Rey don Enrique ${ }^{37}$.

Tres años más tarde, el 21 de julio de 1385, el rey Juan I dicta en su testamento que desea ser enterrado en la capilla que su padre había fundado en la Catedral de Toledo. También reafirma que los restos de su mujer reposarían allí. La cláusula del testamento de Juan I dice así:

E primeramente encomendamos nuestra ánima á nuestro Señor Dios, que la crió, e la ha de salvar, si la su merced fuese. E mandamos que nuestro cuerpo sea enterrado en la Iglesia Catedral de la dicha cibdad de Toledo, en la capilla dó son enterrados los cuerpos del Rey nuestro señor é padre, é de la Reyna nuestra madre, que Dios perdone: é la nuestra sepultura sea delante el altar de la Imagen de la Asuncion de Sancta Maria, que está á par del otro altar dó son enterrados los cuerpos del Rey nuestro padre, é de la Reyna nuestra madre. Otrosi, por quanto la Reyna Doña Leonor mi muger, que Dios perdone, ordenó é mandó en su Testamento, que fuese enterrado el su cuerpo á dó nos ordenasemos nuestra sepultura, é por quanto agora está en depósito, en la dicha capilla, por nuestro mandado, nos, por complir su voluntad, ordenamos é mandamos, que su cuerpo sea enterrado, en aquel lugar dó está en deposito, cerca de aquel lugar, dó está la nuestra sepultura delante del sobredicho altar de la Asuncion de Sancta Maria, en tal manera que la su sepultura esté á la nuestra mano izquierda ${ }^{38}$.

\footnotetext{
${ }^{36}$ Archivo de esta Real Capilla, gav. 14, leg. 1 , n. ${ }^{\circ}$ 6. Segovia. Era 1420, año 1382, recogido por: Hidalgo 1975, p. 403.

${ }^{37}$ López de Ayala, Crónica del Rey don Juan Primero, p. 160.

${ }^{38}$ Ibidem, p. 414.
} 
Cinco años más tarde el rey Juan I fallece, y como había establecido en su testamento fue enterrado en la capilla toledana:

E el cuerpo del rey don Juan fincó en la capilla de las casas del arzobispo de Toledo en Alcalá: é estovo y con el cuerpo la Reyna Doña Beatriz, su muger, é con ella el arzobispo de Sigüenza, fasta que despues le levaron á Toledo á enterrar en la capilla quel Rey don Enrique, su padre ficiera en la iglesia de Sancta Maria de la dicha cibdad ${ }^{39}$.

En el año 1391 ya bajo el reinado de Enrique III de Castilla encontramos un nuevo acontecimiento de relevancia para la historia de la capilla. En esa fecha la judería de Toledo fue asaltada y masacrada. Recordemos que Enrique II establece en su testamento que el modo de financiación de la capilla se haría a través de la cabeza del pecho de los judíos. Así fue hasta 1391, según Hidalgo Lucero, los capellanes tuvieron una dotación de cuarenta y ocho mil cuatrocientos maravedís anuales de moneda vieja ${ }^{40}$ hasta que la dotación fue perdida con el saqueo de la judería. En ese año de 1391, tras haberse quedado sin fondos, el capellán mayor, Juan Martínez, solicitó al rey una solución. Hasta mayo de 1397 no se redactó un documento por el cual Enrique III decidió que en lugar de los 48.400 maravedíes que recibía la capilla al año, se les concederían las rentas que el rey recibía de los arciprestazgos de Illescas, Canales y Rodillas ${ }^{41}$. Y aun esí esta solución no llegó a hacerse efectiva hasta el año 1446 bajo el reinado de su hijo Juan II $^{42}$.

Estando el rey Enrique III en Toledo en el año 1406, durante la preparación de una campaña militar contra Granada, cayó enfermo. El rey dictó testamento y la muerte le sobrevino el 25 de diciembre de ese año. Tras su defunción fue enterrado, vestido con el hábito de San Francisco, en la capilla real de Toledo ${ }^{43}$. En su precipitado testamento fechado el 24 de diciembre de 1406, el rey Enrique III hace una serie de referencias a la capilla:

Mando que mi cuerpo sea enterrado en la Iglesia catedral de Sancta Maria de Toledo, en la capilla donde están enterrados los cuerpos de mi abuelo e abuela y el Rey don Juan mi padre, e la Reyna doña Leonor mi madre (...) la sepultura mando que sea hecha de la manera e obra que yo mande hacer las sepulturas de los Reyes mi abuelo e mi padre (...) e mando que para encima de la dicha sepultura que hagan hacer una tumba asegún la yo mande hacer a cada una de las otras dichas sepulturas. (...) Otrosi por quanto la

${ }^{39}$ Ibidem, p. 344.

${ }^{40}$ Hidalgo 1975, p. 406.

${ }^{41}$ Ibidem, p. 407.

${ }^{42}$ Ibidem, p. 408.

${ }^{43}$ González Dávila 1638, p. 203. 
capilla en que yo me mando enterrar no esta acabada mando que mis testamentarios la acaben y la hagan acabar ${ }^{44}$.

A raíz de esta última afirmación, la profesora Pérez Higuera, discrepando con la mayor parte de la historiografía que data la finalización de la capilla en el año 1379 , deduce que las obras no fueron terminadas antes de 1406 y especula que su finalización completa tuvo lugar ya bajo la regencia de Catalina de Lancaster ${ }^{45}$, algo que veremos con más detalle en nuestro análisis arquitectónico.

La reina Catalina de Lancaster decidió proveer una segunda plaza de Capellán mayor al frente de otros ocho capellanes en el panteón Trastámara ${ }^{46}$. El 17 de agosto de 1415 la regente instauró una segunda capilla para si misma en la catedral nombrando primer capellán mayor a Pedro Rodríguez de Moya ${ }^{47}$. Es posible que a nivel arquitectónico esta fundación fuera acompañada de la finalización de las obras, que no habían sido concluidas aún en 1406. Tres años más tarde la reina fallecía siendo la última persona en ser enterrada en el mausoleo.

Ya en el siglo XVI, la capilla se convirtió en un obstáculo para la celebración de ciertas ceremonias de la Catedral. Su localización en el extremo de la nave septentrional complicaba el tránsito de las procesiones. El arzobispo Fonseca, se reunió entonces con el deán y cabildo de la iglesia para debatirlo. Del debate se consideró acudir a Carlos V con el fin de que se les otorgara licencia para trasladar la capilla a un nuevo espacio con mayor ornato y decencia ${ }^{48}$. Para ello se eligió una herrería adosada al ábside junto a la capilla de Santiago ${ }^{49}$. En el año 1531, previa venida del Emperador Carlos V, se sacó el nuevo proyecto a concurso. Los dos maestros implicados fueron Diego de Siloé y Alonso de Covarrubias y fue este último quien se hizo con el proyecto e inició las obras que finalizaron tres años más tarde ${ }^{50}$. Cabe mencionar que cuando Carlos $\mathrm{V}$ visitó la nueva obra, no quedó muy conforme pues según dice en su libro Diego Vázquez, el emperador entrando a vella antes de la traslación dixo que era buena aquella capilla para un mercader rico ${ }^{51}$.

El emperador, a pesar de su descontento, dotó una real cédula fechada el día 23 de mayo de 1534 por la cual ordenó al cardenal Juan Pardo de Tavera que

${ }^{44}$ López de Ayala, Crónica del Rey Enrique Segundo, p. 264.

45 Pérez Higuera 1985, p. 132.

46 Pérez Grande 2001, p. 253.

47 Villarroel 2008, p. 315. En este caso debemos interpretar el término "capilla" como institución (capellanías y cargos secundarios) o como dotación de ornamentos y objetos litúrgicos. Véase a este respecto: Nieto 2013.

${ }^{48}$ Hidalgo 1975, p. 421.

${ }^{49}$ Gudiol 1947, p. 72.

${ }^{50}$ Ibidem, p. 73.

${ }^{51}$ Hidalgo 1975, p. 424. 
los cuerpos de los reyes fueran trasladados. Como recogió en su publicación Lucio Hidalgo Lucero, existen dos versiones distintas de cómo aconteció la traslación de los cuerpos reales: la primera es de Baltasar Porreño. El autor explica cómo:

El Cardenal [Tavera], a esta sazón, se hallaba en Alcalá de Henares, y siéndose mostrada la real cédula del Emperador mandó a su Vicario General que era el doctor Blas Ortíz (...) hiciese la dicha traslación..., $\mathrm{y}$ el orden que se dio fue el siguiente: que el jueves siguiente que se contaban veintiocho días de mayo, se acompañase con el obrero maior de la iglesia y con los visitadores de la Fábrica, y con una dignidad, un canónigo, un regidor y jurado de la ciudad y delante de todas estas personas y dos escribanos públicos del número, fuese a la capilla y reconociese los cuerpos reales y los sacase de donde estavan, y con la decencia y autoridad que convenía, los depositase en la misma capilla antigua, y otro día con procesión solemne los mudase a la capilla nueva, lo cual se hizo y cumplido puntualmente, con mucho acompañamiento de canónigos y gente principal ${ }^{52}$.

Sin embargo Diego Vázquez, al igual que posteriormente Cristóbal Lozano, probablemente influido por las palabras de Vázquez, narran el acontecimiento de un modo distinto:

Una tarde el 28 de mayo de 1534, acabando los capellanes de decir su Nocturno, entró en la capilla muy acompañado de gente y oficiales canteros y carpinteros, el mariscal de Navarra, corregidor que era a la sazón en esta ciudad, y dixo a los capellanes quehastaahíhabíandefendidoysolicitadoquelacapillanosemudase, suplicándolo muchas veces a su majestad, que luego se saliesen de la capilla, que según lo que yo después entendí, apenas se les dio lugar de recoger a la sacristía lo que por ahí habia, viendo que ya la cosa carescía de remedio, y como los oficiales venían advertidos de lo que avían de hazer, subió muy agudo un carpintero o pedrero a descalzar una cabeza de una viga gruesa que era estribo de la armadura de los artesones, y haciendo fuerza por desencajar la viga, la misma viga al salir de su lugar le dio en los pechos y vino al suelo muerto; no dejó de mirarse en esta desgracia o castigo, quel primer hombre que comenzase a deshacer aquel edificio muriese luego allí a los primeros golpes ${ }^{53}$.

Nos encontramos ante dos testimonios que aunque distintos no son incompatibles. En primer lugar ambos coinciden con que el traslado aconteció el 28 de mayo de 1534. En segundo lugar, el violento acontecimiento del derribo de la viga, podría suponerse posterior al solemne traslado de los cuerpos. Aceptando el 28 de mayo de 1534 como el momento de traslación, la

52 Ibidem, p. 425.

${ }^{53}$ Ibidem, p. 426. 
pregunta es: ¿cuándo fue derribado el mausoleo? Bajo el testimonio de Diego Vázquez, parece que la intención del mariscal de Navarra y su equipo era derribar la capilla, pero no tenemos constancia documental de que el derribo fuera efectuado por completo. Por otro lado, encontramos nuevos documentos fechados en el año 1587, descubiertos por Filemón Arribas Arranz en el archivo de Simancas, que prueban que la capilla no fue destruida inmediatamente en 1534 sino con posterioridad a 1587.

Dichos documentos dan fe de un conflicto acontecido entre las capellanías de Reyes Nuevos, es decir la instituida por Enrique II y continuada por sus descendientes, y la capellanía de la reina doña Catalina. Ambas instituciones estaban reunidas en el mismo lugar y en el mismo momento en la Capilla de Reyes Nuevos construida por Covarrubias, y por lo tanto la simultaneidad de los oficios daba lugar a discusiones sobre preferencias. Según la documentación, los capellanes de los reyes nuevos solicitaron a su majestad que:

se rehabilitase para el culto y se destinase a los capellanes de doña Catalina un lugar en que antiguamente había estado instalada la capilla de Reyes Nuevos que está agora cerrado con un tabyque en el cual, entre otros enterramientos estuvo el de la propia reina fundadora ${ }^{54}$.

Según el autor, el expediente fue sometido a informe de García de Loaisa y del Licenciado Rades de Andrada, quienes en marzo y junio de 1588 dieron sus respectivas opiniones. Sin embargo esta rehabilitación no llegó a efectuarse.

Estos documentos dan prueba de que en el año 1587, la capilla antigua fundada por Enrique II no había sido derribada sino cubierta por un muro de tapial (está agora cerrado con un tabyque). El estado de conservación en el año 1588 sería sin embargo realmente pobre, dado que el culto era impracticable y las opciones de restauración fueron desestimadas. Cabe hacerse una última pregunta de la que no hemos logrado obtener respuesta. ¿La capilla fue demolida inmediatamente después de 1587, al desestimar la solicitud de restauración, o fue abandonada?

\section{ESTUDIO ARQUITECTÓNICO}

Tras haber realizado este amplio recorrido documental del edificio, vamos a intentar hacer una reconstrucción de cómo pudo ser la capilla, en la medida de lo que las fuentes lo permitan. Como hemos visto, la principal fuente visual del edificio es el plano del manuscrito de Juan López de León. Todos los estudios hasta la fecha han sido realizados sobre dicho plano. Sin

${ }^{54}$ Arribas 1944-1945, p. 205. 
embargo este plano data de la década de los treinta del siglo XVI, ciento cincuenta años después de la construcción del mausoleo, por lo que el edificio pudo experimentar modificaciones. Nosotros, sin duda vamos a basarnos en el plano de López de León, pero vamos a intentar reinterpretarlo, deteniéndonos en algunos de los principios que se han aceptado sin condiciones. Con ello pretendemos enriquecer el conocimiento arquitectónico de este edificio.

\subsection{La sala de la torre}

La capilla real estaría localizada sobre los dos últimos tramos de la nave septentrional del templo catedralicio. A estos dos tramos, según el plano de López de León, se le añadiría un tercer espacio a occidente que ocuparía la sala sobre la que se levanta la torre de la catedral. Ésta sala occidental es hoy en día la capilla del tesoro y en adelante en nuestro estudio la llamaremos sala de la torre. Este espacio está cubierto por una bóveda dorada de mocárabes de raigambre hispano musulmana ${ }^{55}$ pero de difícil datación. Las anotaciones de Juan López de León sobre el plano acerca de la sala de la torre rezan:

Por la labor que hoy se muestra en alto de esta sacristía se puede entender que tal debiera ser la labor que cubría el cuerpo de este edificio de la capilla, y bien me acuerdo haberla visto, que eran unos artesones y pinas de gran cuerpo todo dorada y azul, bien es decir que se cumplió en la labor y en todo lo demás la voluntad de su fundador don Enrique, rey virtuoso / así se llevara todo adelante lo que a esta real capilla y a su dotación de horas que dejo el rey don Enrique III su nieto tocaba ${ }^{56}$.

Además haciendo referencia a su acceso, encontramos una segunda leyenda que reza: puerta para entrar aqui que era la sacristía que está debajo de la torre, los canónigos dicen misa en ella ahora ${ }^{57}$.

A raíz de estas anotaciones en el plano, la historiografía ha concluido dos hechos que no han sido cuestionados desde el siglo XVI. Por un lado que el espacio actuaba como sacristía de la capilla y por otro lado que la bóveda de mocárabes que cubre la sala de la torre era parte de la capilla (fig. 3). En primer lugar si aceptamos las palabras de Juan López de León, este espacio actuaría como sacristía en torno a 1534, lo que no quiere decir que fuera proyectado como tal ciento cincuenta años antes, o incluso no quiere decir que fuera parte activa de la capilla fundada por Enrique II.

${ }_{55}$ Ruiz 2006, p. 15.

${ }_{56}$ Arellano 2010, p. 22.

${ }^{57}$ Ibidem. 


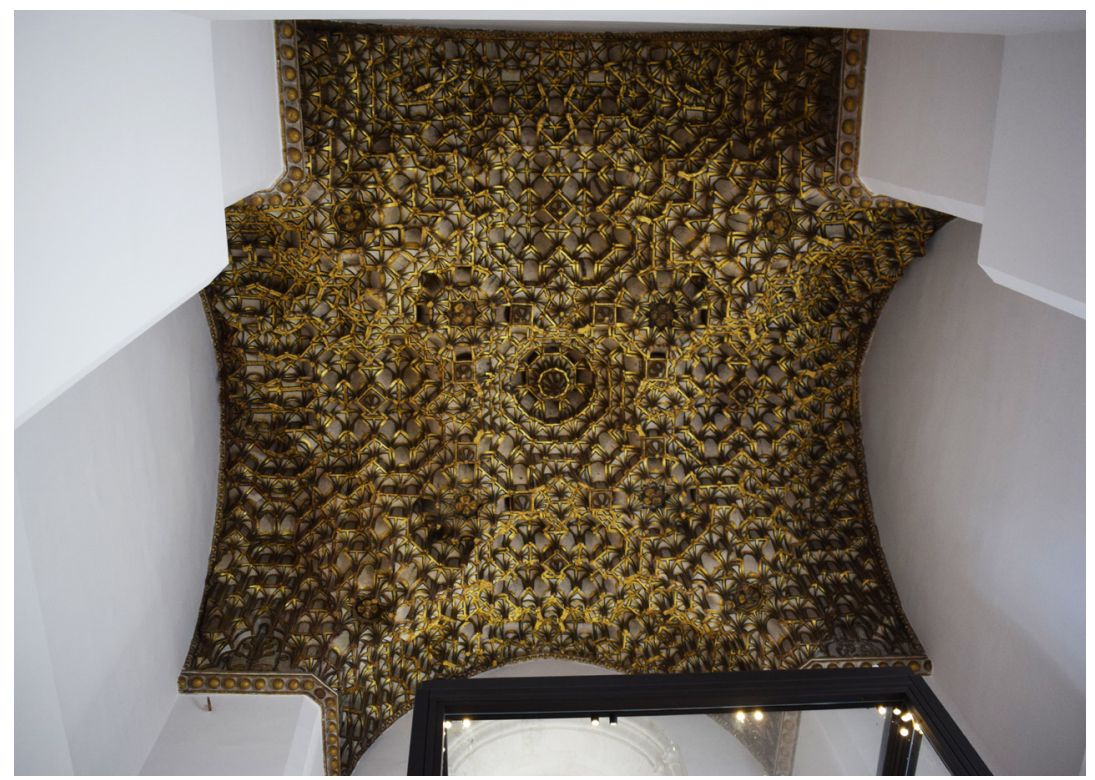

Fig. 3. Bóveda de mocárabes sobre la Sala de la Torre de la Catedral de Toledo. (C) GumielCampos.

Por otro lado, con respecto a la bóveda de mocárabes que cubre este espacio, encontramos dos hipótesis en juego. La mayor parte de la historiografía coincide en que esta bóveda ha estado localizada de modo permanente en el espacio que hoy en día ocupa. En base a esto, la sala de la torre era parte de la capilla original de Enrique II y la bóveda de mocárabes era un testimonio de cómo podía ser el resto de la cubrición del mausoleo ${ }^{58}$. Ángela Franco Mata sin embargo consideró que la bóveda de mocárabes fue trasladada posteriormente desde otro de los espacios de la capilla, probablemente el tramo más monumental ${ }^{59}$. Ciertamente, hemos encontrado un argumento que desestima la primera hipótesis, posicionándonos en una opinión cercana a la de Franco Mata: a través de un artículo de José María Gutiérrez Arias ${ }^{60}$, hemos conocido que sobre el artesonado se dispone una potente bóveda de crucería cuyas nervaduras y clave cuentan con decoración (fig. 4), lo que demuestra que originalmente la sala de la torre debió ser proyectada con una bóveda gótica propia de la época y que la armadura de mocárabes fue instalada posteriormente. Los historiadores sin embargo coinciden en que esta armadura data del siglo XIV,

${ }^{58}$ Ruiz 2006, p. 15.

${ }^{59}$ Franco 2010, p. 195.

${ }^{60}$ Gutiérrez 2014. 
momento fundacional de la capilla. Pero en nuestra opinión, la morfología de sus mocárabes y la composición del trazado en sí nos hacen pensar que sea algo posterior, probablemente avanzado el siglo XV.

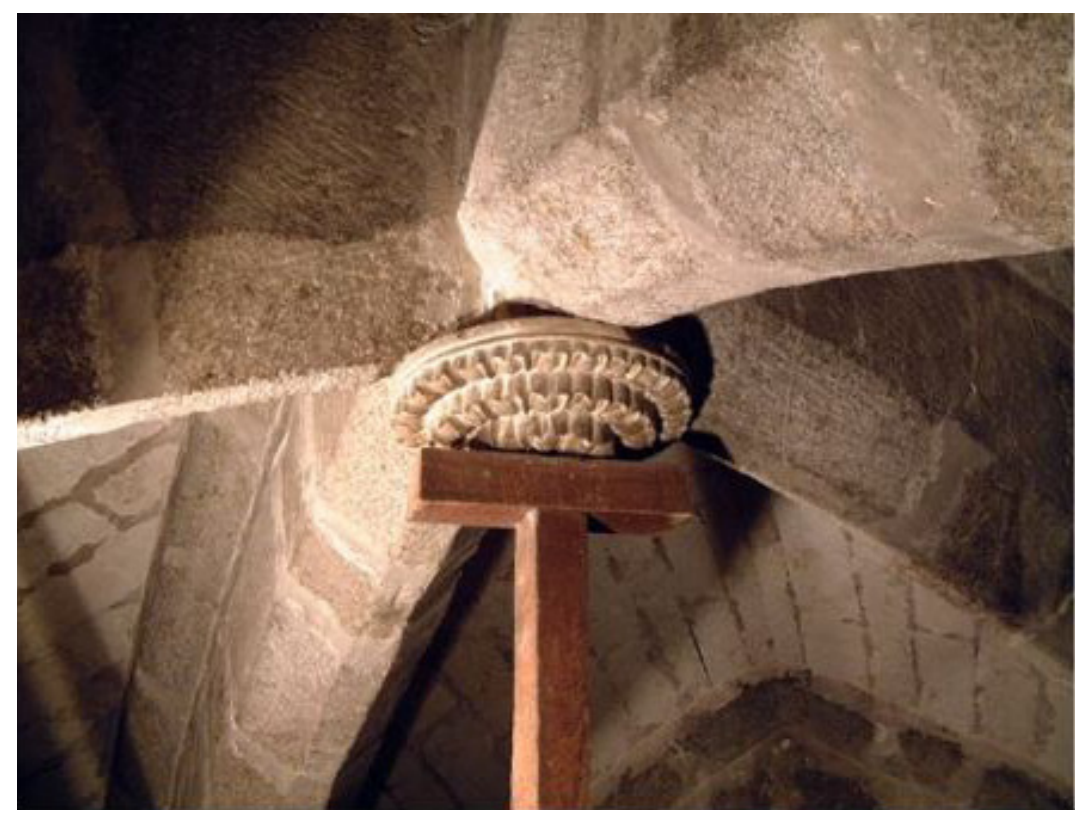

Fig. 4. Clave de la Bóveda de crucería sobre la sala de la Torre de la Catedral de Toledo. Fotografía de Gutierrez Arias.

Por último, para complicar la interpretación de la sala de la torre, debemos mencionar otra anomalía. Cuando observamos su distribución en planta (fig. 5), la sala no está dispuesta en continuidad y simetría con los dos tramos restantes de la capilla, sino que esta notablemente desplazada hacia el norte. Esta anomalía parece mostrarnos que la sala de la torre fue construida en un momento diferente a los dos tramos anteriores, y que probablemente no era parte de la capilla en 1382.

Sí es posible que las obras de la base de la torre y los trabajos en la capilla sean prácticamente contemporáneos, sin embargo no responden a un proyecto conjunto y único. Debe de ser ya en el siglo XV, cuando la sala de la torre se integró dentro del servicio de la capilla, actuando entonces como sacristía. Cabría plantear que esto ocurriera en el momento en que Catalina de Lancaster instauró su nueva capilla dentro del mismo ámbito. La necesidad de espacio para contrarrestar el aumento de eclesiásticos para el servicio de la capilla pudo ser el detonante de que la sala de la torre se añadiera. Es posible incluso que sea en ese momento cuando el artesonado se colocara. 


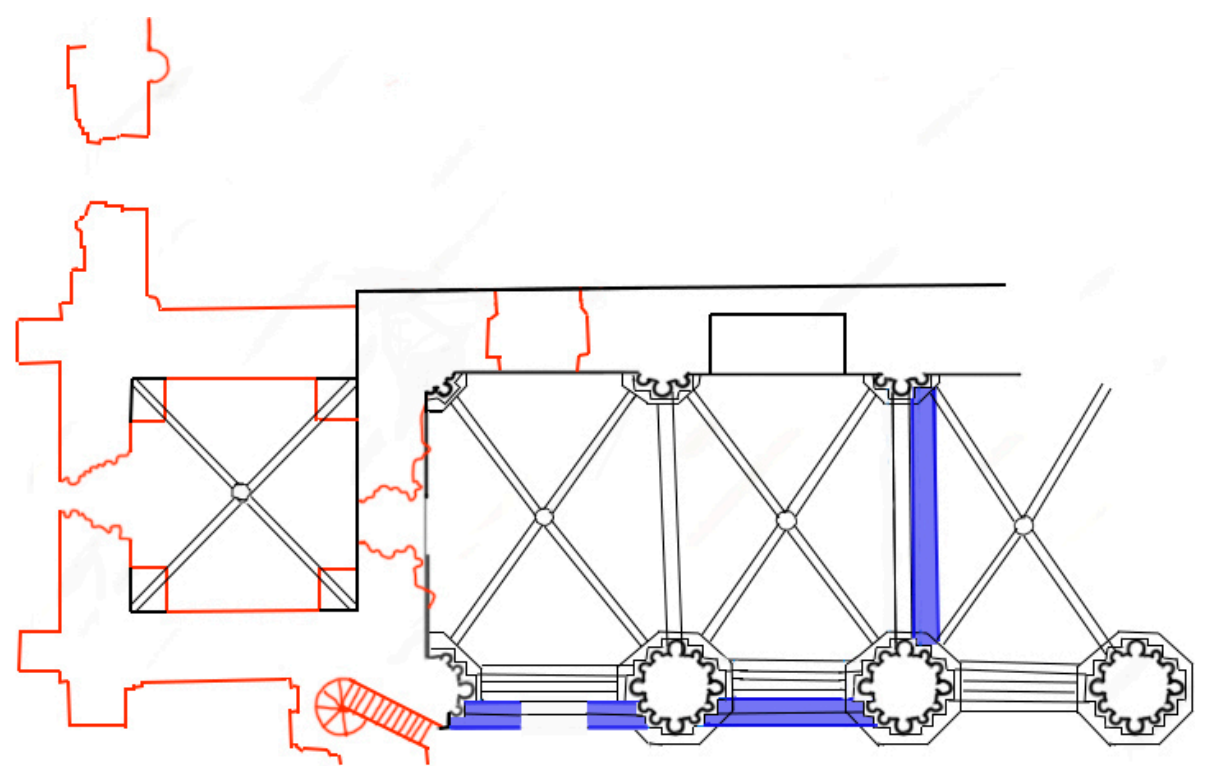

Fig. 5. Planta Hipotética de la Capilla Real de la Catedral de Toledo.

Concepción Abad Castro, 2018.

\subsection{El coro de la capilla}

Saliendo de la sala de la torre, nos dirigimos al primer tramo de la nave más septentrional de la catedral, el que se ha considerado el primer tramo de la capilla. En el plano de López de León, a ambos lados de la puerta de acceso a la sala de la torre, encontramos dos breves apuntes que dicen: asientos de los capellanes. A raíz de esta anotación se ha aceptado que éste fuera el espacio dedicado al coro ${ }^{61}$.

Es bastante aceptable pensar que este espacio fuera reservado para el coro de la capilla, sin embargo encontramos de nuevo una anomalía que debemos plantear. Este tramo se encontraba abierto tanto en sus flancos norte y sur por dos entradas. En el plano de López de León se escriben dos datos en las respectivas puertas: la sur reza puerta principal, la norte salida a la claus$\operatorname{tra}^{62}$. El claustro de la catedral de Toledo fue levantado bajo el mecenazgo del obispo Tenorio, quien fue obispo de Toledo entre 1377 y $1399^{63}$. La primera

\footnotetext{
${ }^{61}$ Hidalgo 1975, p. 420

${ }^{62}$ Arellano 2010, p. 24.

${ }^{63}$ Bango 2005, p. 26.
} 
piedra del claustro fue colocada el 14 de agosto de 1389, y la construcción se dio por terminada en $1397^{64}$. Esto significa que las obras del claustro fueron prácticamente contemporáneas a las obras de la capilla real. Nos tenemos que plantear por tanto, si la puerta de acceso al claustro en este tramo que estamos estudiando, fue contemporánea a la capilla, e incluso proyectada a la vez, o si fue abierta con posterioridad en algún momento entre 1397 y 1534.

Ciertamente si esta puerta estuviera abierta desde la inauguración del claustro, supondría una problemática para la privacidad de la capilla fundada por Enrique II. Los oficios de los capellanes se verían interrumpidos ya que el tramo de capilla que llamamos el coro, sería uno de los dos únicos espacios de tránsito hacia el claustro de la catedral. Debemos cuestionarnos en primer lugar cuándo fue abierto el vano al claustro, pero las formas de la puerta que hoy en día tenemos no nos pueden ayudar a su datación ya que son mucho más tardías. Tampoco es extraño que hubiera en el siglo XIV y principios del XV un solo acceso al claustro. En el caso de que el vano sí fuera abierto en una etapa temprana, deberíamos preguntarnos si la puerta permanecería cerrada durante los oficios. Por la ausencia documental no podemos dar respuesta a todas estas preguntas y de momento decidimos posicionarnos de modo paralelo al grueso de la historiografía, aceptando que este primer espacio del mausoleo fuera el coro de la capilla así como el acceso a la misma desde la catedral.

\subsection{El panteón regio}

El tercer y último tramo de la capilla, el más oriental, estaba reservado al panteón regio, el espacio sin duda de mayor relevancia, y también el de mayor complejidad en su estudio. Empecemos por la distribución de los altares (fig. 6). Toda la historiografía coincide en resaltar que el panteón estaba flanqueado por tres altares, el altar mayor divido en dos por un cortinaje y los dos laterales situados en los muros norte y sur de la capilla ${ }^{65}$.

En el plano de Juan López de León encontramos unas anotaciones colocadas en dos cuadros diferentes a la altura del altar mayor representando dos altares distintos en los cuales se escribió: Ntra. Sra. de la Asunción y / como dio la casulla ${ }^{66}$. Este altar, como podemos ver también en el plano, estaba elevado sobre dos gradas que lo separaba del piso donde se distribuían los sepulcros.

${ }^{64}$ Ibidem, p. 28.

${ }^{65}$ Lozano 1734, p. 66.

${ }^{66}$ Arellano 2010, p. 24. 


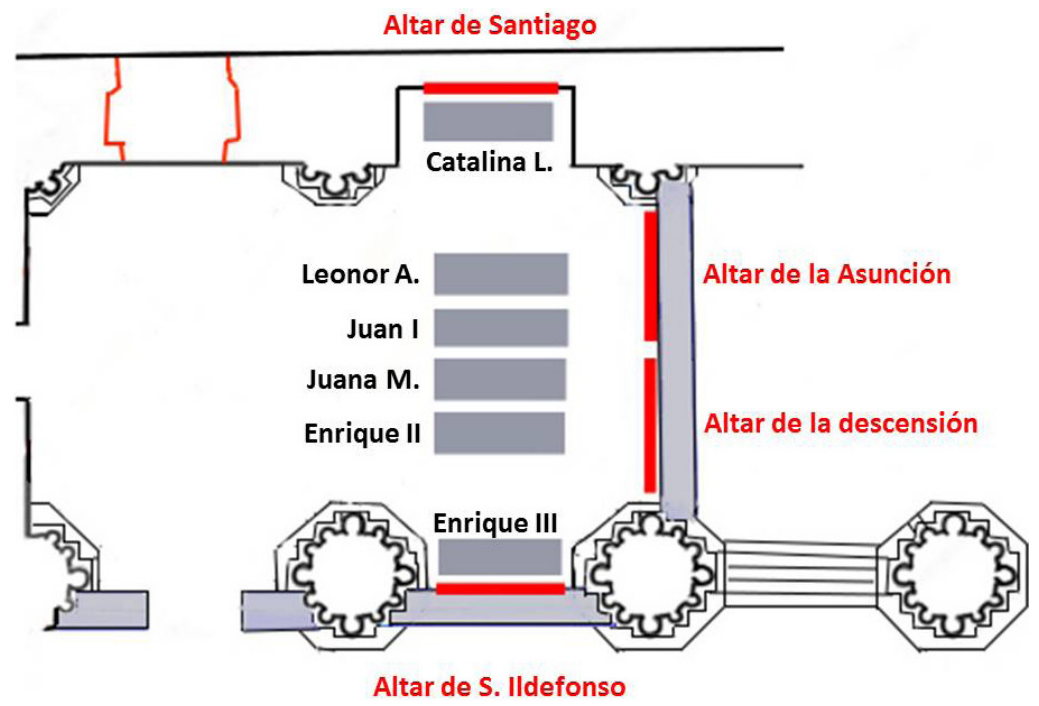

Fig. 6. Posible distribución de los altares y sepulcros de la Capilla Real de la Catedral de Toledo. (C) GumielCampos.

Los altares laterales estaban situados entre los pilares de la catedral. El del lado del evangelio, estaba dedicado al apóstol Santiago. Enfrentado a éste se situaba el altar dedicado a San Ildefonso, en cuyo retablo se mostraba como daba la Virgen la casulla a San Ildefonso ${ }^{67}$, un tema ciertamente apropiado para su localización bajo el pilar de la descensión de la Virgen.

Una vez comprendida la distribución de los altares, con la cual coincidimos con la opinión de toda la historiografía, vamos a analizar la distribución de los sepulcros y su problemática (fig. 6). La documentación prueba que en el mausoleo Trastámara fueron enterrados tres reyes y tres reinas de Castilla de tres generaciones consecutivas. En líneas generales se ha aceptado que la distribución de los sepulcros era la siguiente: en el suelo, ante las gradas del altar mayor, y entre los altares laterales, se ordenaban simétricamente cuatro sepulcros con los pies orientados hacia el altar y la cabeza hacia occidente. La distribución de estos sepulcros de izquierda a derecha mirando hacia el altar, o si se prefiere de norte a sur era: sepulcro de Leonor de Aragón, sepulcro de Juan I, sepulcro de Juana Manuel y sepulcro de Enrique II. Así ciertamente aparece reflejado en las anotaciones del plano de Juan López de León.

Por otro lado, bajo el altar de Santiago se colocó el sepulcro de la reina doña Catalina de Lancaster, nieta de Pedro I y esposa de Enrique III.

${ }^{67}$ Hidalgo 1975, p. 419. 
La anotación del plano del XVI reza: aquí había un altar del apóstol Santiago, que era el enterramiento de la reina doña Catalina y aqui estaba enterrado su cuerpo. Era el altar de sus capellanes ${ }^{68}$. El último rey que nos queda por situar por lo tanto es Enrique III. Toda la historiografía ha aceptado que su sepulcro estaba situado en el lado opuesto al de su esposa, es decir bajo el altar con advocación a San Ildefonso. Sin embargo, la publicación de Arellano García en el año 2010 ha abierto una nueva vía de interpretación. Arellano García, ha probado que la leyenda que reza en el plano acerca del altar de San Ildefonso es la siguiente: aquí había un altar como daba Ntra. Sra. la Casulla a san Ildefonso, y era antes el enterramiento del rey don Enrique II. Y aqui está su cuerpo. Resaltemos que la mención es al enterramiento de Enrique II y no Enrique III. En primer lugar nosotros hemos cotejado que no se trata de un error de transcripción de Arellano García. Se podría plantear tan solo que fuera un error de López de León a la hora de escribir el plano, pero aun así nos vemos en la obligación de plantear la hipótesis de que realmente el cuerpo del rey Enrique II estuviera situado allí.

Si atendemos de nuevo al testamento de Enrique II, el monarca dice:

para que sea enterrado honradamente, como de Rey, en la Iglesia de Sancta Maria de Toledo, delante de aquel lugar do anduvo la Virgen Sancta Maria é puso los piés quando dió la vestidura á Sancto Alfonso ${ }^{69}$.

Las palabras de Enrique II especifican que su enterramiento fuera hecho delante del pilar de la descensión, y en plano, el lugar más próximo a esta definición ciertamente es bajo el altar de San Ildefonso. Se podría en base a esto plantear la posibilidad de que el cuerpo de Enrique II pudiera haber sido enterrado bajo el pilar de la descensión originalmente.

Sin embargo, una vez expuesta esta hipótesis que se planteó a lo largo de nuestras investigaciones vamos a desestimarla. Solo podríamos aceptar que el cuerpo fuera enterrado bajo el pilar de la descensión entre 1380 y 1385 , ya que un documento de mayor relevancia que el plano del siglo XVI, nos prueba la localización del cuerpo de Enrique II. Se trata del testamento del rey Juan I del año 1385. En el mismo, el monarca escribe:

é la nuestra sepultura sea delante el altar de la Imagen de la Asuncion de Sancta Maria, que está á par del otro altar dó son enterrados los cuerpos del Rey nuestro padre, é de la Reyna nuestra madre $^{70}$.

${ }^{68}$ Arellano 2010, p. 24.

${ }^{69}$ López de Ayala, Crónica del Rey Enrique Tercero, p. 39.

${ }^{70}$ López de Ayala, Crónica del Rey don Juan Primero, p. 414. 
En definitiva por lo tanto coincidimos con la distribución de los cuerpos reales planteada por todos los historiadores, al menos desde el año 1385 . No descartamos sin embargo que en algún intervalo de tiempo entre 1380 y 1385, el cuerpo del rey Enrique II fuera trasladado unos metros, y que en origen hubiera sido depositado ciertamente bajo el pilar de la descensión.

Conocemos cómo eran cuatro de los seis sepulcros reales del panteón Trastámara (fig. 7) ya que los originales fueron trasladados a la capilla construida por Covarrubias entre 1531 y 1534, y pese a que fueron dorados y retocados por Pedro López de Texeda ${ }^{71}$, nos dan una idea de cual pudo ser su estado original. Los sepulcros de Juan I y Leonor de Aragón se perdieron y en la capilla de Covarrubias fueron sustituidos por dos estatuas orantes labradas en 1534 por Jorge de Contreras ${ }^{72}$. En su traslado, los yacentes sufrieron ciertas modificaciones. Se rehicieron la mayoría de los ángeles que están situados en los ángulos de los sepulcros. Además en la estatua yacente de Enrique II se rehízo la mano derecha, sin guante, añadiendo un cetro nuevo ${ }^{73}$.

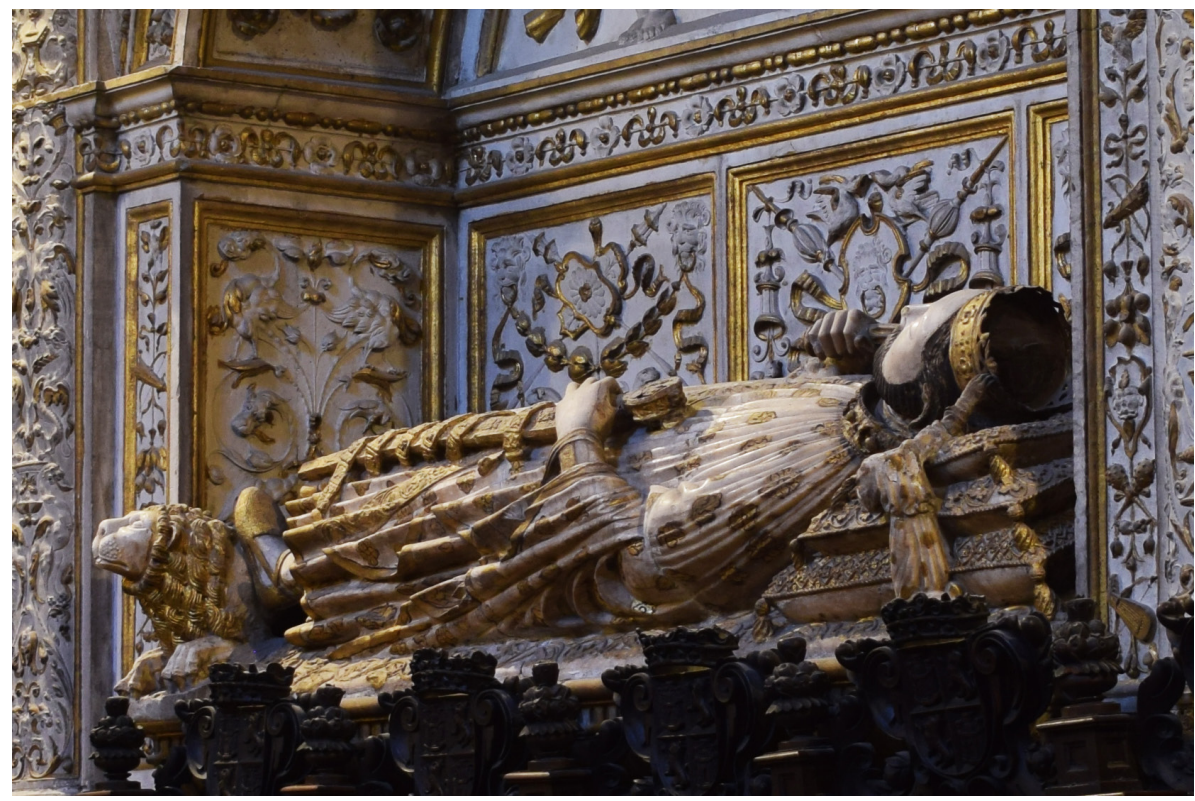

Fig. 7. Sepulcro de Enrique II, actualmente en la Capilla de Reyes Nuevos. (C) GumielCampos.

${ }^{71}$ Hidalgo 1975, p. 432.

72 Gudiol 1947, p. 74.

${ }^{73}$ Pérez Higuera 1985, p. 134. 
Como hemos analizado anteriormente, la datación de dichos sepulcros se deduce en base al testamento del rey Enrique III del año 1406. Recordemos cómo el monarca castellano afirma:

la qual sepultura mando que sea hecha de la manera e obra que yo mande hacer las sepulturas de los reyes mi abuelo e mi padre, que Dios perdone; emando que para encima de la dicha sepultura que hagan hacer una tumba asegún la yo mande hacer a cada una de las otras dichas sepulturas, e un paño de oro para poner encima della e cobrirla ${ }^{74}$.

A raíz de este testamento la profesora Pérez Higuera dedujo que todas las estatuas yacentes sepulcrales de la capilla son obra de Enrique III. En base a esto los bultos de sus abuelos y padres serían previos a 1406, mientras que el suyo propio y el de su esposa sería algo posterior a $1406^{75}$.

Esta idea se reafirma además a través de la autoría de las figuras. Hasta el año 1985 fueron atribuidas erróneamente a un maestro Anrique, sin embargo la profesora Pérez Higuera, descubrió en las obras las firmas de dos escultores, el maestro Luys y el maestro Pedro Rodríguez, quienes participaron activamente en el taller toledano bajo los obispados de Pedro Tenorio (1377-1399) y de Pedro de Luna (1399-1415) ${ }^{76}$. Las firmas están situadas en la almohada inferior de las tres sobre las que se apoyan las cabezas de los monarcas. Estas almohadas están cubiertas con recargada decoración a base de formas geométricas y lobuladas encerrando motivos heráldicos y vegetales. Las firmas de dichos escultores rezan $M^{o}$ luys/entallador en el sepulcro de Enrique II; $m e$ fecit $\mathrm{m}^{\%}$ po $r s$ o sea Pero Rodrigues, en el de Juana Manuel y $m$ luis de nuevo en el de Catalina de Lancaster ${ }^{77}$.

Las cuatro esculturas presentan un modelo iconográfico muy similar además de unas características muy semejantes en cuanto al estilo y la técnica. En los cuatro sepulcros el rey o la reina aparecen reposando en posición yacente, acompañados de figuras de ángeles que se sitúan a los pies y a la cabeza del difunto. La principal diferencia entre unas y otras viene marcada por la indumentaria. Mientras que Enrique II y su esposa Juana Manuel visten ricas vestimentas cargadas de decoración, Enrique III y Catalina de Lancaster visten los hábitos franciscano y dominico respectivamente ${ }^{78}$.

${ }^{74}$ López de Ayala, Crónica del Rey Enrique Segundo, p.265.

${ }^{75}$ Pérez Higuera 1985, p. 132.

${ }^{76}$ Ibidem, p. 131.

77 Ibidem, p. 135.

${ }^{78}$ Ibidem, p. 134. 


\subsection{La cubrición de la capilla, origen gótico y posterior artesonado plano de piñas}

La cubrición es probablemente la principal incógnita sobre el conjunto, pero vamos a plantear alguna hipótesis al respecto: el dato más cercano al conocimiento de la misma es de Juan López de León quien recordemos afirmaba:

Por la labor que hoy se muestra en alto de esta sacristía (en referencia a la sala de la torre) se puede entender que tal debiera ser la labor que cubría el cuerpo de este edificio de la capilla, y bien me acuerdo haberla visto, que eran unos artesones y pinas de gran cuerpo todo dorada y azul, bien es decir que se cumplió en la labor y en todo lo demás la voluntad de su fundador don Enrique, rey virtuoso $^{79}$.

A raíz de esta afirmación los historiadores han insistido en que se trataba de una obra "mudéjar" de tiempos de Enrique II. La asociación de las obras de la Capilla Real de Córdoba a Enrique II y su supuesta preferencia por la estética hispanomusulmana, ha empujado a los historiadores del arte a conferir esta estética a la obra toledana. Sin embargo ya hemos planteado que la obra toledana debió ser cubierta en tiempos de Catalina de Lancaster.

Sin duda existió un artesonado que cubrió la capilla. No se puede dudar de la palabra de Juan de León, quien afirmó ver claramente unos artesones y pinas de gran cuerpo todo dorada y azul. También, como hemos visto, Diego Vázquez, al narrar el intento de destrucción de la capilla por parte del Mariscal de Navarra, afirma como subió muy agudo un carpintero o pedrero a descalzar una cabeza de una viga gruesa que era estribo de la armadura de los artesones. Ambos son argumentos suficientes para demostrar que en el siglo XVI existía un artesonado, sin embargo no nos parece acertado atribuir esta techumbre al programa de Enrique II sino a Catalina de Lancaster como vamos a intentar demostrar.

La clave para la interpretación de dicho artesonado se encuentra en la misma afirmación de Juan de León quien recuerda haber visto unas piñas. Un reciente artículo de Álvaro Fernández de Córdova ha demostrado como durante los reinados de Enrique III y Catalina de Lancaster se comenzaron a utilizar divisas vinculadas a los miembros de la familia real, es decir símbolos representativos que se salían de la heráldica oficial. El rey Enrique III adoptó el cordón de San Francisco mientras que la reina Catalina asumió la piña

${ }^{79}$ Arellano 2010, p. 22. 
como divisa representativa ${ }^{80}$. La existencia de una divisa atribuida a Catalina de Lancaster se documenta en una carta real de 1410 que prohíbe su uso sin autorización y aunque en ella no se especifica la forma del emblema, se ha identificado con la piña la cual proyectaba un mensaje de fecundidad e incidía en la prosperidad de un reino dotado de heredero. Encontramos numerosas representaciones de esta divisa en el monasterio de Santa María la Real de Nieva (Segovia) y también en las propias almohadas del sepulcro de la reina en la real capilla que estamos tratando ${ }^{81}$.

Pero sin duda el ejemplo más representativo es la Sala de la Galera en el Alcázar de Segovia. Esta sala fue ordenada construir durante los primeros años de su regencia y fue acabada en 1412. La estancia servía de antesala al trono y estaba notablemente monumentalizada. En el techo, la reina dejó impresa su memoria mediante una inscripción pero también cuatro grandes piñas incrustadas en la cubierta, recordando precisamente el valor de su maternidad, clave de la legítima sucesión de Juan II en aquel complicado interregno ${ }^{82}$.

La Sala de la Galera nos puede servir como un paralelo mucho más suntuoso y monumental de la cubrición de la capilla de Toledo. Cabe pensar que la cubierta del mausoleo Trastámara, de carácter más discreto, fuera plana. Las palabras de Diego Vázquez que describen el suceso acaecido durante el intento de derribo relatan que el desafortunado carpintero subió a descalzar una cabeza de una viga gruesa que era estribo de la armadura de los artesones, es decir a retirar la viga que va de lado a lado a lo largo de la armadura. Esta viga es propia de artesonados planos y no de bóvedas de mocárabes. La cubrición plana además sería más acorde al espacio rectangular que englobaba la capilla.

Podemos afirmar por lo tanto que el artesonado desaparecido fue colocado durante el reinado de Catalina de Lancaster como demuestra la utilización de la piña como divisa representativa. Sería instalado muy probablemente a partir de 1415, momento en el que se instituye la nueva capellanía de la reina. Este artesonado respondería al gusto "mudéjar" de la Castilla del siglo XV, una estética que se aleja mucho de las cubriciones de mocárabes del siglo XIV, que en muchas ocasiones eran proyectadas por los propios arquitectos nazaríes. Cabe plantearse incluso que el proyecto original de Enrique II para su capilla, contemplara crucerías góticas de piedra vista, las mismas que cubrían entonces la propia catedral de Toledo (fig. 8), y así permanecería la capilla entre 1380 y 1415.

${ }^{80}$ Fernández de Córdova 2016, p. 114.

${ }^{81}$ Ibidem, p. 121.

${ }^{82}$ Ibidem, p. 126. 


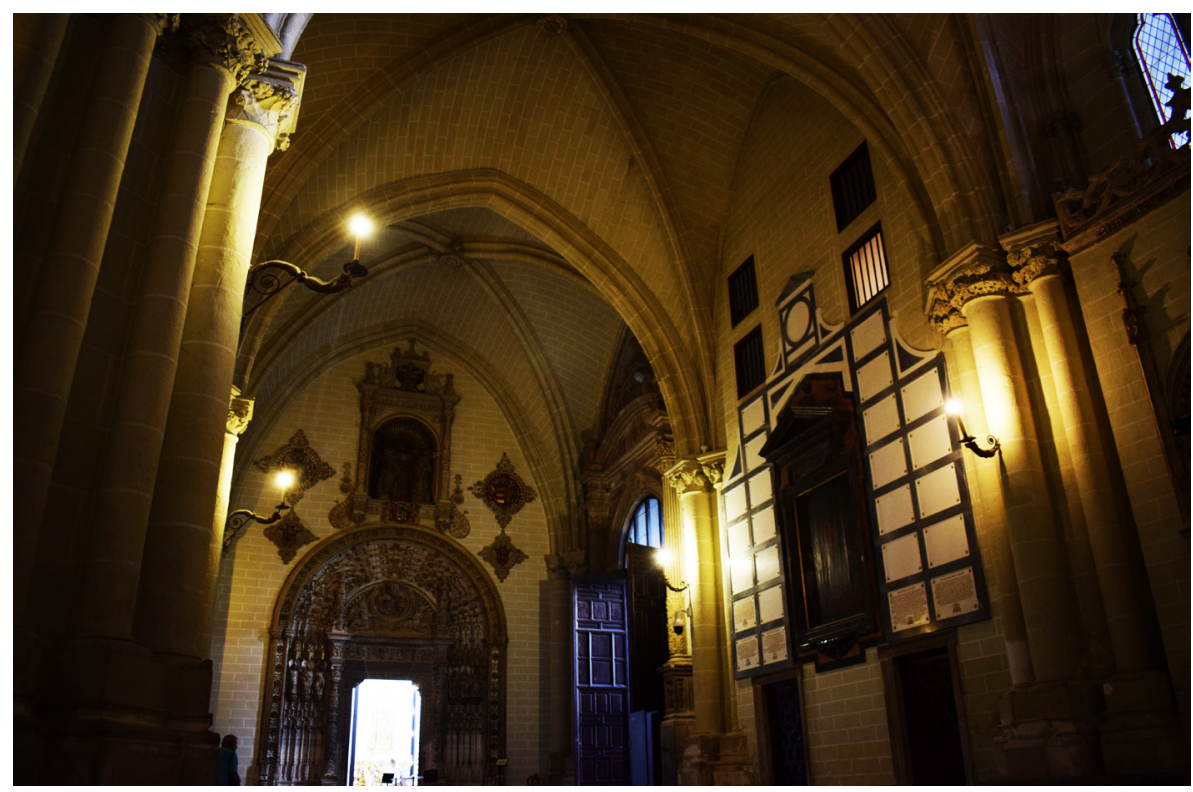

Fig. 8. Estado actual del espacio de la catedral donde se situaba la Capilla Real.

(C) GumielCampos.

\section{CONCLUSIONES}

El edificio fue indudablemente fundado por Enrique II de Castilla en el año 1374 a raíz de lo establecido en la cláusula segunda de su testamento, sin embargo su fundación no implica ni mucho menos la culminación del edificio. Las obras debieron iniciarse bajo su reinado, o el de su hijo Juan I, pero no fueron terminadas hasta la regencia de Catalina de Lancaster e incluso el reinado de su bisnieto Juan II. Cabe pensar que Enrique II fuera enterrado provisionalmente bajo el pilar de la descensión, pero en 1385 tenemos constancia asegurada de su presencia frente al altar.

La capilla a nivel institucional debió entrar en pleno funcionamiento en el año 1382, tras la dotación de Juan I, y el entierro de su madre Juana Manuel un año antes. Consideramos sin embargo, que los doce capellanes que ya habían sido establecidos por su padre por orden testamentaria pudieran estar ejerciendo desde febrero de 1380, ya que parece extraño que el cuerpo del rey permaneciera sin su culto. El 21 de julio de 1385, momento en el que Juan I dicta testamento, la capilla ya debe contar con cierta estructura formal, pues el rey ordena que los cuerpos sean enterrados alineados frente a los altares. 
Cabe pensar que las obras se paralizaran tras los pogromos de 1391, momento en el que la capilla pierde su financiación. Consideramos que entre 1391 y 1415 , el edificio estaba aún incompleto o no suficientemente monumentalizado. Sin embargo, en el año 1406 los trabajos de los sepulcros ya estaban en marcha y la reanudación de la estructura arquitectónica había sido ordenada a través del testamento de Enrique III.

Finalmente, en agosto de 1415, la reina regente doña Catalina funda una nueva capilla dentro de la de Reyes Nuevos. Aunque no tenemos pruebas documentales, consideramos que las obras fueron culminadas en torno a esta fecha y por orden de Catalina de Lancaster. Desde el entierro de la propia reina en 1418, la obra posiblemente estuviera completamente concluida, hasta que en 1531 el arzobispo Fonseca decide sustituirla. El 28 de mayo de 1534 los cuerpos de los reyes y las reinas son trasladados al nuevo edificio construido por Covarrubias y el Mariscal de Navarra inicia la destrucción del antiguo. Sin embargo, esta destrucción no pudo ser completada ya que en 1587 los capellanes de Reyes Nuevos, emplazados desde hace 50 años en la capilla de Covarrubias, solicitan que se restaure la capilla primitiva de Enrique II para el servicio de los capellanes de la reina Catalina de Lancaster. La solicitud queda desestimada y el edificio bien es demolido de modo definitivo, o bien expuesto a la ruina.

A nivel arquitectónico lo primero que debemos concluir es que si existió un proyecto fundacional planteado por Enrique II, éste no tuvo nada que ver con el resultado final de la reina Catalina de Lancaster, pues la capilla no comenzó a tomar forma hasta el reinado de Juan I. Consideramos que la capilla en origen solo contaba con dos espacios consecutivos, uno de acceso a modo de vestíbulo que se puede considerar el coro, y otro espacio más monumental que albergaba el panteón regio. La disposición de las tumbas se planteó en tiempos del rey Juan I, sin embargo se trataba de sarcófagos no monumentales recogidos entre tres altares a los lados norte, sur y este. En tiempos de Enrique III, estos sarcófagos se monumentalizaron con estatuas yacentes.

Finalmente en tiempos de Catalina de Lancaster, probablemente en torno a 1415, la capilla fue cubierta con un artesonado dorado y azul con representaciones de piñas. Es posible que en este momento, se concibiera incluir la sala de la torre en el programa formal de la capilla para que actuara como sacristía. Esta idea gana solvencia si tenemos en cuenta que un nuevo grupo de capellanes ocuparían el espacio desde 1415 y que el ámbito requerido era mayor. 


\section{BIBLIOGRAFÍA CITADA}

Abad Castro, Concepción (2001), Espacios y capillas funerarias de carácter real, en Bango Torviso, Isidro G. (coord.), Maravillas de la España Medieval. Tesoro sagrado y monarquía, León, Junta de Castilla y León, pp. 63-71.

Amador de los Ríos, José (1845), Toledo Pintoresca o descripción de sus más celebres monumentos, Madrid, Imprentas y librerías de D. Ignaccio Boix.

Arco, Ricardo del (1954), Sepulcros de la Casa Real de Castilla, Madrid, Consejo Superior de Investigaciones Científicas - Instituto “Jerónimo Zurita".

Arellano García, Mario (2010), Las Capillas Reales de la Catedral Primada: Sancho IV, "Toletum, Boletín de la Real Academia de Bellas Artes y Ciencias Históricas de Toledo" 57, pp. 9-39.

Arribas Arranz, Filemón (1944-1945), Noticias sobre las capillas antigua y moderna de Reyes Nuevos de la Catedral de Toledo, "Boletín del Seminario de Estudios de Arte y Arqueología" 11, pp. 205-207.

Bango Torviso, Isidro (2005), La catedral de Toledo hacia 1400. Un centro creador en constante transformación, en La capilla de San Blas de la Catedral de Toledo, Madrid, Fundación Iberdrola, pp. 21-32 (Colección Cuadernos de Restauración, 11).

Blas Ortiz (1999), Descripción Graphica y Elegantísima de la S. Iglesia de Toledo, en Gonzálvez, Ramón; Pereda, Felipe (eds.), La Catedral de Toledo 1549, según el Doctor Blas Ortiz, Descripción Graphica y Elegantisima de la S. Iglesia de Toledo, Toledo, Antonio Pareja editor, pp. 9-77.

Canabal Rodríguez, Laura (2007), La capilla de los Reyes Nuevos de la Catedral de Toledo: adiciones y constituciones otorgadas por Felipe II, "Toletana, Cuestiones de Teología e Historia" 17, pp. 157-195.

Casas, Ignacio de las (1992), El conocimiento de la arquitectura en la Catedral de Toledo, Madrid, Departamento de Expresión gráfica arquitectónica - Escuela Técnica Superior de Arquitectura de Madrid (tesis doctoral).

Cerro Malagón, Rafael del (1992), Arquitecturas de Toledo. Del Romano al gótico, Toledo, Servicio de Publicaciones de la Junta de Comunidades de Castilla-La Mancha.

Chueca Goitia, Fernando (1981), La Catedral de Toledo, León, Everest.

Colomina Torner, Jaime (2003), Capilla de Reyes de la Catedral de Toledo. Documentos inéditos de obras realizadas entre 1654 y 180, "Anales toledanos" 39, pp. 127-142.

Fernández de Córdova Miralles, Álvaro (2016), El cordón y la piña. Signos emblemáticos y devociones religiosas de Enrique III y Catalina de Lancaster (1390-1418), "Archivo Español de Arte” 89, pp. 113-130. 
Franco Mata, Ángela (1991), Toledo Gótico, en Peris Sánchez, Diego (coord.), Arquitecturas de Toledo, vol. I., Toledo, Servicio de Publicaciones de la Junta de Comunidades de Castilla-La Mancha.

Franco Mata, Ángela (2010), Las Capillas, en Gonzálvez Ruiz, Ramón (dir.), La Catedral Primada de Toledo, Dieciocho siglos de Historia, Toledo, Promecal Publicaciones.

Fernando González Romero, José (2014), Catedral de Toledo, la Dives Toletana y la batalla de las catedrales gigantes en el gótico clásico, Gijón, Ediciones Trea.

González Dávila, Gil (1638), Historia de la vida y hechos del rey don Henrique tercero de Castilla, ínclito en religión y justicia. Al muy católico y poderoso señor don Felipe quarto, rey de las Españas y Nuevo Mundo, Madrid, Francisco Martínez editor.

Gudiol Ricart, José (1947), La Catedral de Toledo, los monumentos cardinales de España, vol. II, Madrid, Editorial Plus Ultra.

Gutiérrez Arias, José María (2014), Sobre el tesoro, Consorcio de Toledo. Ayudas a la rehabilitación [en línea], http://www.consorciotoledo. org/sobre-la-capilla-del-tesoro/ [consulta: 15/11/2018].

Hidalgo Lucero, Lucio (1975), La Real Capilla de Reyes Nuevos de Toledo. Apuntes históricos y artísticos, "Boletín Oficial del Arzobispado de Toledo" 131, pp. 399-444.

Lop Otín, María José (2008), Los "espacios” de la catedral de Toledo y su funcionalidad durante la Edad Media, en Vizuete Mendoza, José C.; Martín Sánchez, Julio (coords.), Sacra loca toletana. Los espacios sagrados en Toledo, Cuenca, Universidad de Castilla-La Mancha, pp. 223-262.

López de Ayala, Pero, Crónica del Rey don Juan Primero de Castilla, ed. de Cayetano Rosell, en Crónicas de los reyes de Castilla desde don Alfonso el sabio, hasta los católicos don Fernando y doña Isabel. Tomo II, Madrid, M. Rivadeneyra editor, 1877.

López de Ayala, Pero, Crónica del Rey don Pedro I con las enmiendas del Secretario Gerónimo Zurita y las correcciones y notas añadidas por Don Eugenio de Llaguno y Amirola, caballero de la Orden de Santiago, de la real academia de la Historia, ed. de Cayetano Rosell, en Crónicas de los reyes de Castilla desde don Alfonso el sabio, hasta los católicos don Fernando y doña Isabel. Tomo I, Madrid, M. Rivadeneyra editor, 1875.

López de Ayala, Pero, Crónica del Rey Enrique Segundo de Castilla, ed. de Cayetano Rosell, en Crónicas de los reyes de Castilla desde don Alfonso el sabio, hasta los católicos don Fernando y doña Isabel. Tomo. II, Madrid, M. Rivadeneyra editor, 1877. 
López de Ayala, Pero, Crónica del Rey Enrique Tercero de Castilla, ed. de Cayetano Rosell, en Crónicas de los reyes de Castilla desde don Alfonso el sabio, hasta los católicos don Fernando y doña Isabel. Tomo II, Madrid, M. Rivadeneyra editor, 1877.

López de Ayala-Álvarez de Toledo, Jerónimo (1919), Catalogo Monumental y Artístico de la Catedral de Toledo, Toledo, Diputación Provincial de Toledo.

Lozano, Cristóbal (1734), Los Reyes Nuevos de Toledo. Describense las cosas más augustas y notables de esta Ciudad Imperial: quienes fueron los Reyes Nuevos, sus virtudes, sus hechos, sus proezas, sus hazañas; y la Real Capilla que fundaron en la Santa Iglesia, mausoleo sumptuoso, donde descansan sus cuerpos, Madrid, Imprenta de Andrés Ramirez.

Nieto Soria, José Manuel (2013), Los espacios de las ceremonias devocionales y litúrgicos de la monarquía Trastámara, "Anales de Historia del Arte" 23, pp. 243-258.

Nogales Rincón, David (2009), La representación religiosa de la monarquía castellano-leonesa: la capilla real (1252-1504), Madrid, Universidad Complutense de Madrid (tesis doctoral).

Pérez Grande, Margarita (2001), Los Reyes y la Catedral de Toledo, en Bango Torviso, Isidro G. (coord.), Maravillas de la España Medieval. Tesoro sagrado y monarquía, León, Junta de Castilla y León, pp. 253-259.

Pérez Higuera, María Teresa (1985), Los sepulcros de los Reyes Nuevos (Catedral de Toledo), "Tekné, revista de arte" 1, pp. 131-139.

Ruiz Souza, Juan Carlos (2006), Capillas Reales funerarias catedralicias de Castilla y León: nuevas hipótesis interpretativas de las catedrales de Sevilla, Córdoba y Toledo, "Anuario del Departamento de Historia y Teoría del Arte (U.A.M.)" 18, pp. 9-29.

Villarroel González, Óscar (2008), Capilla y capellanes reales al servicio del rey en Castilla. La evolución en época de Juan II (1406-1454), "En la España Medieval” 31, pp. 309-356.

Fecha de recepción del artículo: enero 2020

Fecha de aceptación y versión final: julio 2020 